\title{
A Web como fonte de informação para a cadeia produtiva do leite
}

\section{The Web as an information source for the milk production chain}

\author{
Pricila Estevão; ${ }^{1}$ Diego Neves de Sousa ${ }^{2}$; José Benedito Pinho ${ }^{3}$
}

\section{Resumo}

Este artigo analisa a estrutura, o conteúdo e o tipo de informação divulgada em um Website especializado na cadeia produtiva do leite. Para este estudo, escolheu-se o portal Milkpoint, criado e explorado comercialmente pela AgriPoint Consultoria Ltda., desde 2001, com o propósito de contribuir para a formação do moderno produtor de leite, fundamentalmente, por meio da oferta da informação necessária à sua evolução. $\mathrm{O}$ estudo é de natureza exploratória e qualitativa. Entre os resultados, o estudo postula que o conteúdo existente no portal é predominantemente escrito, necessitando de um melhor tratamento da informação, tanto no aspecto gráfico como estético, bem como pela necessidade do uso eficiente da linguagem multimídia e hipertextual, que é própria da Web.

Palavras-chave: World Wide Web (Web). Cadeia produtiva do leite. Divulgação científica.

\begin{abstract}
This article analyzes the structure, content and type of information disclosed in a Website specializing in milk production chain. For this study, was chosen the Milkpoint Portal, created and exploited commercially Agripoint Consultoria Ltda., since 2001, with the aim of contributing to the formation of the modern milk producer, fundamentally through the provision of information to its evolution. The study is exploratory and qualitative. Among the results, the study postulates that the content in the portal is predominantly written, requiring better information processing, both in the graphic and aesthetic aspects, as well as the need for efficient use of multimedia language and hypertext, which is itself the Web.
\end{abstract}

Keywords: World Wide Web (Web). Milk production chain. Science communication.

\section{Introdução}

O período de intensas transformações na dinâmica social e econômica constitui o marco da chamada Sociedade da Informação, na qual, as novas condições tecnológicas anunciam a breve superação da era industrial. A geração, o processamento e a transmissão de informação constituem uma base fundamental para o desenvolvimento científico, tecnológico e social e, de maneira prática, são, também, imprescindíveis à tomada de decisão em todas as esferas da sociedade.

\footnotetext{
${ }^{1}$ Mestre em Extensão Rural pela Universidade Federal de Viçosa. Possui graduação em Comunicação Social pela Universidade Estadual de Londrina. Atualmente desenvolve suas atividades de relações públicas no Núcleo de Comunicação Organizacional da Embrapa Gado de Leite. Email: pricila.estevao@embrapa.br

${ }^{2}$ Gestor de Cooperativas, Mestre em Extensão Rural pela Universidade Federal de Viçosa. Atualmente é analista na área de transferência de tecnologia da Embrapa Pesca e Aquicultura. Email: diegocoop@hotmail.com

${ }^{3}$ Possui graduação em Publicidade e Propaganda pela Pontifícia Universidade Católica de Campinas, especialização em Proyectos de Comunicación Investigación y Planific pelo Centro Internacional de Estudios Superiores de Comunicación. Mestrado em Ciências da Comunicação pela Universidade de São Paulo e doutorado em Ciências da Comunicação pela Universidade de São Paulo. Atualmente é Professor Associado da Universidade Federal de Viçosa. Email: jbpinho@ufv.br
} 
Os setores ligados à agropecuária - em conjunto com os demais setores da economia brasileira utilizam os meios de comunicação como uma das fontes para obter informação (seja de natureza técnica, científica ou gerencial) e, do ponto de vista estratégico, para aprimorar seus processos produtivos e, consequentemente, aumentar sua competitividade no mercado. Porém, cada vez mais, como salienta Viero e Souza (2008), o mundo rural engaja-se na realidade da constante transformação própria do espaço urbano e, dessa maneira, está se inserindo na Sociedade da Informação, utilizandose de novas técnicas e instrumentos que facilitam a troca de informações e a tomada de decisão.

Entretanto, conforme pesquisa conduzida pela Embrapa Gado de Leite, foi diagnosticado que a comunicação para a transferência de tecnologia na atividade leiteira sofre sérias limitações e gargalos (VILELA; BRESSAN; CUNHA, 2001; ESTEVÃO, 2011). Esse estudo apontou que as informações tecnológicas geradas pela pesquisa agropecuária não chegavam a uma parte significativa dos produtores de leite brasileiros. Para esses autores, isso deveu-se a vários fatores, tais como a grande dispersão desses produtores no território nacional, o baixo número de profissionais para prestar o serviço de assistência técnica e extensão rural e a escassez de oportunidades e canais de comunicação na maioria das regiões de produção de leite.

Segundo dados do Censo Agropecuário IBGE (2006), o Brasil tem por volta de 1,3 milhão de produtores de leite, dispersos por todos os estados brasileiros e o número de profissionais para prestar assistência técnica e extensão rural está aquém, considerando a demanda e o tipo de acompanhamento rural que precisa ser desempenhado.

Assim, a premissa adotada é que a rede mundial poderia ser um meio de comunicação e de informação viável e eficaz para atingir públicos de interesse da cadeia produtiva do leite, ou mesmo para atuar, de forma complementar, nos canais de comunicação já tradicionais para o público rural, a exemplo dos eventos técnicos, dias de campo, treinamentos presenciais e publicações especializadas.

O número de usuários de internet divulgado pelo Ibope para o terceiro trimestre de 2012 foi da ordem de 94,2 milhões, o que torna o Brasil o quinto país com maior número de conexões à internet. Nesta comparação com os demais países, o país continua registrando a maior expansão do acesso à internet domiciliar (IBGE, 2012). No setor agropecuário brasileiro, por sua vez, o número de sites aumentou, substancialmente, nos últimos anos, pois passou de 600 endereços agropecuários nacionais, no final de 1999, para 2.878 sites registrados em 2002 (BOTEON, 2004).

Com relação à internet, a pesquisa TIC (Tecnologia da Informação e Comunicação) Domicílios 2008 revelou que 20\% dos lares brasileiros na área urbana tinham conexão à rede, enquanto isso, apenas $4 \%$ dos domicílios da zona rural possuíam conectividade. Portanto, o uso das novas tecnologias, de modo especial a internet, ainda encontra-se em fase de descoberta, tanto no âmbito teórico como metodológico. Isto é, ao mesmo tempo em que a rede se oferece como um novo e sedutor campo a ser explorado, os seus recursos devem ser estudados e avaliados (OLIVEIRA, 1997, p. 6).

Nesse sentido, este artigo objetivou analisar a estrutura, o conteúdo e as formas de divulgação da informação técnico-científica e gerencial em um site especializado na cadeia produtiva do leite. Para este estudo de caso, escolheu-se o Milkpoint (http://www.milkpoint.com.br), um portal vertical ${ }^{4}$

\footnotetext{
${ }^{4}$ Um portal, é "um site na Internet que funciona como centro aglomerador e distribuidor de conteúdo para uma série de outros sites ou subsites dentro, e também fora, do domínio ou subdomínio da empresa gestora do portal" Entre outras classificações, os portais podem ser horizontais ou verticais. Os horizontais permitem acesso a vários tipos de informação e serviços; já os verticais concentram links para conteúdo sobre um assunto específico, como é o caso do Milkpoint (WIKIPEDIA, 2012).
} 
criado e explorado comercialmente, desde 2001, pela AgriPoint Consultoria Ltda ${ }^{5}$ Um dos primeiros serviços lançados pela empresa, o portal MilkPoint oferece acesso gratuito, mas o cadastramento é obrigatório para o usuário. O site tem em seu conteúdo informações técnicas e de mercado para a cadeia produtiva do leite, reúne 60 mil pessoas cadastradas, de todos os estados do Brasil e de quase 60 países, segundo dados primários deste estudo extraídos em 2009.

Tendo em vista a evolução constante e a modernização da produção agropecuária, os responsáveis pelo portal consideram ser imprescindível que o produtor tenha mais eficiência na produção, ganhando competitividade; que se conscientize como participante da cadeia produtiva, muito além da "porteira"; e que acompanhe as tendências do mercado consumidor e as mudanças que ocorrem no setor. Partindo desses pressupostos, o portal Milkpoint visa, com sua missão, contribuir, decisivamente, para a formação desse moderno produtor. A sua importância para a cadeia produtiva do leite está, principalmente, na sua maior expressão e na confiabilidade que desfruta entre os usuários.

A partir da observação direta, foram analisadas a arquitetura da informação e as funcionalidades próprias do portal objeto deste estudo (design, navegabilidade e canais de interação), bem como os tipos de fontes de informação utilizadas (profissionais de instituições públicas, privadas, de ensino, pesquisadores, consultores), os temas e assuntos abordados no conteúdo nele disponibilizado.
Entende-se, aqui, que o conhecimento mais aprofundado da estrutura e da natureza da informação disponibilizada e dos modos de sistematização dos conteúdos informativos, técnicos e científicos no portal permite uma melhor comunicação, trazendo contribuições efetivas para identificar formas mais adequadas para atingir o público rural, em especial, os produtores de leite.

\section{Metodologia}

O estudo é de natureza exploratória e qualitativa. Seu objetivo é o de descrever e analisar o portal Milkpoint, utilizando o confronto com o referencial teórico que será apresentado nos tópicos a seguir, focalizando os seguintes temas: arquitetura da informação e usabilidade (conteúdo e estética), divulgação científica e informação gerencial; levando em consideração os seguintes critérios de avaliação: tipo de informações (gerenciais e técnicocientíficas), natureza da informação (informativa ou opinativa), tipo de linguagem (escrita, audiovisual, multimídia), forma de escrita (linear, reticular ou mista), fontes utilizadas (pública ou privada), formas de interação e temáticas abordadas.

Compreendeu três momentos de análise, seguindo os princípios orientadores da ISO 9241-11 ${ }^{6}$ . Em um primeiro momento, foram analisados 180 conteúdos (notícias e artigos) de 12 links da seção Cadeia Produtiva ${ }^{7}$, localizada no menu esquerdo do site, por tratar de informações diversificadas. A segunda análise foi feita com 10 conteúdos da

\footnotetext{
${ }^{5}$ A AgriPoint é uma empresa de consultoria em agronegócio, e tem como principal foco de atuação as cadeias produtivas do leite, carne bovina, ovinocaprinocultura e cafeicultura. A empresa, fundada no ano 2000, está sediada em Piracicaba-SP e conta com uma equipe de profissionais com experiência em produção, mercado e marketing ligado ao agronegócio. Sua missão é disponibilizar informações e conhecimento sobre as tendências da produção e do mercado no Brasil e no mundo, com o objetivo de aumentar a rentabilidade e a sustentabilidade do agronegócio (CAVALCANTI, 2010).

6 “A ISO 9241-11 define usabilidade e explica como identificar a informação necessária a ser considerada na especificação ou avaliação de usabilidade de um computador em termos de medidas de desempenho e satisfação do usuário. É dada orientação sobre como descrever explicitamente o contexto de uso do produto (hardware, software ou serviços) e as medidas relevantes de usabilidade. A orientação é dada na forma de princípios e técnicas gerais, em vez de requisitos para usar métodos específicos" (INTERNATIONAL ORGANIZATION FOR STANDARDIZATION, 1997, p. 2).

${ }^{7}$ Da seção Cadeia Produtiva, foram analisados os seguintes links: comércio internacional, conjuntura de mercado, dicas de sucesso, editorial, especiais, estatísticas, leite \& saúde, marketing do leite, panorama do mercado, preços do leite, raças e genética e volta ao mundo.
} 
seção Radares Técnicos, por conter artigos técnicocientíficos ligados à produção primária. $\mathrm{O}$ último momento foi a análise de 15 notícias do link Giro Lácteo, por possuir conteúdo dinâmico e de natureza informativa, atualizados diariamente. Todos esses conteúdos foram analisados, com base nos últimos conteúdos focalizados e disponíveis pelo portal no dia 17 de junho de 2009.

\section{Natureza da Internet como Meio de Comunicação}

Parafraseando Castells (1999), a internet não é futuro, é presente. Hoje, as pessoas buscam, avidamente, qualquer tipo de informação pela internet e nela, ainda, encontram outras pessoas, fazem compras, estudam, aprendem e trabalham.

\begin{abstract}
A internet não é simplesmente uma tecnologia; é o meio de comunicação que constitui a forma organizativa de nossas sociedades; é o equivalente ao que foi a fábrica ou a grande corporação na era industrial. A internet é o coração de um novo paradigma sociotécnico, que constitui na realidade a base material de nossas vidas e de nossas formas de relação, de trabalho e de comunicação. O que a internet faz é processar a virtualidade e transformá-la em nossa realidade, constituindo a sociedade em rede, que é a sociedade em que vivemos (CASTELLS, 1999, p. 287).
\end{abstract}

A Web é um espaço de produção, circulação e recepção de informações que modifica, por si só, a estrutura comunicativa tradicional dos meios de comunicação. As pessoas que a acessam podem realizar busca, recuperação, navegação e adição de informações, em um ambiente virtual com liberdade de ação.

Cada meio de comunicação possui sua própria linguagem, e a rede mundial, enquanto novo meio, tem também a sua. Portanto, o conteúdo informacional produzido especificamente para a Web tem que levar em conta suas especificidades. Outro cuidado é com a chamada arquitetura da informação, que consiste na tarefa de estruturar e distribuir as áreas principais e secundárias, tornando as informações facilmente identificáveis, sua distribuição bem definida e a navegação intuitiva (RODRIGUES, 2005).

De uma maneira mais simplificada, Reis (2006) define que o objetivo da arquitetura da informação é criar as estruturas de organização da informação de um Website, para que o usuário consiga compreendê-lo com facilidade. Toub (2000) reforça isto, citando que a arquitetura de informação é a arte e a ciência de estruturar e organizar ambientes informacionais, para ajudar as pessoas a satisfazerem suas necessidades de informação de forma efetiva.

Quanto à linguagem, Pinho (2003) salienta que a $W e b$ oferece amplas possibilidades para o emprego de áudio e de imagens, mas são fundamentalmente as palavras que continuam prevalecendo. No entanto, é certamente o processo de desenvolvimento natural da nova mídia, segundo Bruno Rodrigues, que deverá permitir "aliar texto, design e tecnologia, e tratá-los como um componente único - a informação" (apud PINHO 2003, p. 181).

A informação é a matéria-prima principal da $W e b$, razão pela qual precisa ser trabalhada (conteúdo e linguagem) e disponibilizada (forma e estética), a fim de atender o público ao qual se destina. Neste sentido, Canavilhas (2006) afirma que o trabalho de redação implica jogar com duas variáveis: dimensão (quantidade de dados) e estrutura (arquitetura da notícia).

Ao se falar em estrutura da notícia, os especialistas pensam logo em três possibilidades - lineares, reticulares ou mistas (DIAS; NOCI; SALAVERRIA apud SALAVERRIA, 1999). Na estrutura linear, oleitor é condicionado a um número finito de possibilidades de navegação. $\mathrm{Na}$ estrutura reticular, não existe eixo de leitura definido, mas sim diversas possibilidades garantidas por um formato em rede, onde há espaço livre para escolher o seu percurso único e singular. Já as estruturas mistas apresentam um eixo de leitura (como a estrutura linear), mas várias possibilidades de individualidade em seu percurso. 
Não se lê, na $W e b$, do mesmo jeito que se faz no meio impresso, motivo pelo qual não se deve escrever do mesmo jeito no meio impresso. O papel absorve luz, enquanto a tela do computador a emite. A partir deste ponto, começam as diferenças. Para Nielsen e Loranger (2007), em geral, as pessoas que acessam um site não tendem a buscar informações de uma maneira linear. Em vez disso, contam com pistas visuais que forneçam uma indicação mais forte de que as respostas estão logo ali. Então, elas direcionam a atenção a essas áreas e ignoram as demais.

A Web é considerada um excelente meio de divulgação e recuperação de informação; contudo, é mais adequada para transmitir informação em textos menores, objetivos e concisos, já que as pessoas leem menos na $W e b$. Aos poucos, está se descobrindo a linguagem da nova mídia, em certos aspectos, parecida com a televisão, em outros com o rádio, de outro lado, ela não se parece com nada que se tenha conhecido até então (NIELSEN; LORANGER, 2007).

Um estudo conduzido pelo cientista Lycos David Hendry (apud RICH, 1999) reforçou que, na Web, a escrita deve ser resumida, com parágrafos e sentenças curtas, e a página deve ter muito espaço em branco Nessa mesma linha de pensamento, para que a escrita seja eficiente na $W e b$, (DUBE, 2001; PINHO, 2006) sugerem o uso de subtítulos e bullets ${ }^{8}$ para separar textos e ideias, além do emprego de mapas, tabelas e gráficos interativos.

Na mesma perspectiva, tem-se Barbosa (2004). Para a autora, frases em maiúsculas são aceitáveis em títulos e ênfases ou avisos urgentes. É uma boa prática, também, deixar linhas em branco entre parágrafos ou blocos de texto. Dessa forma, o texto fica organizado e mais fácil de ler, mesmo que a mensagem seja longa.

Os conteúdos existentes em um site na Web são classificados por quatro tipos principais: estático, dinâmico, funcional e interativo. O estático é a informação que não está sujeita a mudança, ou pode sofrer uma atualização esporádica e eventual. O conteúdo dinâmico está presente na seção de últimas notícias, atualizadas constantemente; nas reportagens e artigos publicados diariamente; nos links e nas referências disponibilizados no site para os seus usuários. O funcional é dado, principalmente, pelos menus e barras de navegação. Já o conteúdo interativo estimula a interação com os usuários, por meio da lista de endereços de e-mails que facilitam o contato com o editor ou repórteres de uma publicação virtual (PINHO, 2003).

Os estudos realizados por Mendes et al. (2007) indicam critérios básicos para a seleção de informações na $W e b$, entre eles, a autoria e o conteúdo. Para as autoras, esses dois critérios possuem maior importância que os critérios de navegabilidade e de design, quando trata de credibilidade de textos, pois os últimos critérios não influenciam, de forma direta, a credibilidade do conteúdo. Assim, o critério autoria pode ser classificado por tipo de autor: indivíduo ou entidade. A credibilidade do autor indivíduo pode ser conhecida pela sua formação e pela vinculação a alguma instituição renomada. Sobre a entidade, é preciso verificar a reputação da instituição e a credibilidade na área em que atua.

Embora o critério mais citado para a análise de confiabilidade da informação seja a credibilidade do autor, para Sordi, Meirelles e Grijo (2008), há outro tão importante quanto: a credibilidade do conteúdo. Este último critério refere-se às evidências a favor do conteúdo da informação, obtidas por diferentes maneiras, desde as que empregam o julgamento pelo senso comum, até as fundamentadas em sofisticadas técnicas de confirmação da metodologia da pesquisa científica, incluindo a aplicação de modelos estatísticos, probabilísticos, projetos experimentais, entre outros recursos (VEDDER; WACHBROIT, 2003).

Assim, Sordi, Meirelles e Grijo (2008) afirmam

\footnotetext{
${ }^{8}$ O bullet é um símbolo tipográfico, de formato variado - um círculo, um losango, um quadrado preenchido ou vazado ou ainda um asterisco - usado para destacar um bloco de texto ou para sinalizar itens de uma lista de informações, geralmente colocado à esquerda de cada item (ESTEVÃO, 2011).
} 
que a confiabilidade da informação é mensurada com base na análise das variáveis: credibilidade da fonte e credibilidade do conteúdo. Essas duas variáveis influenciam-se mutuamente, ou seja, fontes confiáveis são entendidas como desenvolvedoras de conteúdos confiáveis e conteúdos confiáveis são entendidos como originados de fontes confiáveis (SLATER; ROUNER, 1996).

\section{Informação Gerencial}

A informação é imprescindível à tomada de decisão em todas as esferas da sociedade, incluindo o setor agropecuário. Ela é tão relevante que tem potencial para afetar a decisão que o gerente irá tomar em relação a um objeto lógico de decisão.

Segundo Couto e Macedo-Soares (2004), as informações gerenciais relevantes dividem-se em três campos principais: internas, de mercado e externas.

As informações gerenciais internas dizem respeito ao desempenho ou à produtividade dos processos e métodos, ao prazo, à duração ou ao tempo de ciclo dos processos. São muito importantes, as informações sobre custos, tangíveis ou intangíveis; de processos exclusivamente associados à disponibilização de cada produto e de cada conjunto de produtos

O campo de informações gerenciais de mercado é o conjunto das informações relativas aos interesses de fornecedores de bens e prestadores de serviço, assim como de clientes, consumidores e usuários de bens ou serviços disponibilizados pela organização, a serem considerados, quando estes tomam suas decisões.

O campo das informações gerenciais externas é o conjunto das informações sobre bens ou serviços, nomeadamente conhecimento e capital, disponíveis em entidades físicas ou jurídicas situados no âmbito externo, com as quais se podem formar alianças estratégicas, objetivando melhorar o resultado da organização. Podem ser as organizações que atuam no mesmo nicho de atividade ou em atividades afins ou em atividades complementares; os intermediários de operações e atividades nos mercados físico ou eletrônico; as consultorias; as autoridades governamentais (Executivo, Legislativo e Judiciário); os grupos e entidades não governamentais; as comunidades locais e as universidades e os institutos de pesquisa.

O que importa ressaltar, no contexto rural, é que a escolha por determinadas opções impactam, diretamente, a eficiência administrativa da propriedade, indicando, assim, a importância de agregar informações de qualidade ao processo decisório. Essas informações terão o papel de fornecer possibilidades analíticas, visando, sobretudo, minimizar os riscos e incertezas inerentes ao processo de tomada de decisão nas propriedades rurais (BLUME; MACHADO, 2006).

\section{Informação e Divulgação Científica}

Promover uma adequada estrutura para a divulgação dos pensamentos e dos resultados das investigações científicas e criar fluxos de informação, visando ao cidadão comum, é de fundamental importância para o desenvolvimento social.

Nas sociedades do terceiro milênio, a posição de cada pessoa no contexto social é, cada vez mais, produto da apropriação das informações e conteúdos obtidos e do conhecimento que conseguiu desenvolver ou construir. Neste contexto, a informação é de fundamental importância para a compreensão e geração de novos conhecimentos e desenvolvimento da sociedade, sendo necessária a difusão, a divulgação e o compartilhamento das informações, que ajudem a produzir entre os indivíduos novas significações sociais e posicionamentos políticos frente ao mundo (LEFF, 2004, p. 61).

No mundo da informação globalizada em que vivemos, no qual nem todo cidadão tem acesso ao conhecimento, a reivindicação Baconiana do “conheceré poder" transformou-se em "compartilhar o conhecimento é poder", como indica Chait (1999). 
Neste sentido, o compartilhar deve ser entendido como um processo democrático e participativo, com ações relacionadas à socialização do conhecimento, as quais objetivam estimular, facilitar, empoderar ou proporcionar a troca de conhecimentos e saberes próprios entre os indivíduos.

Apresentar resultados de investigações científicas à sociedade é algo próprio da ciência, pois é assim que a base de conhecimentos da humanidade cresce. Segundo Meadows (1999, p. 7): "a comunicação situa-se no próprio coração da ciência [...] Isso exige que seja comunicada [...] Qualquer que seja o ângulo pelo qual a examinemos, a comunicação eficiente e eficaz constitui parte essencial do processo de investigação científica." Assim, é de suma importância para a sociedade ter acesso ao conhecimento científico, tornando-se, também, evidente o papel social da mediação dessa informação.

No âmbito deste estudo, as duas principais formas de comunicação da ciência - divulgação científica9 ${ }^{9}$ e jornalismo científico - não são a mesma coisa, embora estejam muito próximas. Ambas destinamse ao chamado público leigo, com a intenção de democratizar as informações (pesquisas, inovações, conceitos de ciência e tecnologia). A divulgação científica diz respeito à divulgação extrapares, por conseguinte, dirigida ao público leigo. Podem ser, por exemplo, os fascículos ou uma série de palestras que traduz em linguagem adequada a ciência e a tecnologia para o cidadão comum. Entretanto, o jornalismo científico é um caso particular de divulgação científica, ou seja, é uma forma de divulgação endereçada ao público leigo, uma vez que obedece ao padrão de produção jornalística.

Neste caso específico, o público-alvo do portal Milkpoint pode ser considerado uma audiência intermediária, na medida em que não faz parte da comunidade científica, mas tem conhecimentos técnicos específicos que o diferenciam do leigo. Esta audiência, portanto, pode não dominar a linguagem científica, mas a linguagem técnica do seu cotidiano que é, por vezes, a mesma utilizada pela ciência.

A divulgação da ciência cumpre duas funções básicas: informativa e educativa. A função informativa refere-se à tarefa de exercer a partilha social do saber, função que se reveste de reconhecida necessidade social diante da velocidade com que se acumulam os novos saberes, conquistam novas técnicas, garantem novos procedimentos; levando ao homem comum o conhecimento do qual ele historicamente foi apartado e do qual foi se mantendo, cada vez mais, distanciado, à medida que as ciências se desenvolvem e se especializam (ZAMBONI, 2001). A educativa seria a "importante atividade de contribuir com seu pensamento para a formação da opinião pública" (ACUNA apud ZAMBONI, 2001, p. 49).

Para levar a ciência e a tecnologia ao público leigo, de forma efetiva, a tarefa de maior envergadura é o trabalho de recodificação da linguagem empregada pela ciência. Por isso, para Zamboni (2001), a dificuldade a ser vencida é, fundamentalmente, um problema de comunicação, ou melhor, transformar em inteligível para muitos a linguagem hermética e difícil da ciência, entendida por apenas uns poucos.

\section{Análise e Discussão dos Resultados}

A análise do site MilkPoint foi realizada com base no conteúdo existente nas seções Cadeia Produtiva, Radares Técnicos e Giro Lácteo, no dia 17 de junho de 2009. A seção Cadeia Produtiva, por tratar de informações diversificadas, abrangeu um corpo de 180 conteúdos, entre notícias e artigos. A seção Radares Técnicos publica conteúdo técnico científico ligado à produção primária, com presença

\footnotetext{
${ }_{9}^{9}$ Massarani e Moreira (2005) distinguem 3 linhas na comunicação científica: os discursos científicos primários (escritos por pesquisadores para pesquisadores), os didáticos (como os manuais científicos para ensino) e os de divulgação científica. Enfatizam, também, que cada discurso serve a um propósito determinado e busca atingir um público específico; assim, os textos de divulgação tenderiam a ser mais descritivos, com um estilo mais personalizado e mais próximo da linguagem convencional.
} 
de 10 artigos escritos por especialistas sobre temas da atividade leiteira. Por fim, a seção Giro Lácteo, com 15 notícias publicadas, é fundamentalmente informativa e possui conteúdo dinâmico, atualizado diariamente. Foram adotados, como elementos de análise, o tipo de informações (gerenciais e técnicocientíficas), as temáticas abordadas, as fontes utilizadas e o tipo de escrita (linear, reticular ou mista).

De maneira geral, pode-se dizer que o portal Milkpoint possui conteúdo predominantemente informativo, são 23 links para acesso às informações gerenciais e técnico-científicas. Possui conteúdos dinâmicos, estáticos, funcionais e interativos, com a predominância dos dois primeiros. Esses links de conteúdo são divididos com destaque aos elos da cadeia produtiva do leite ligado à economia (mercado, comercialização e marketing do leite) e à produção primária (dentro da porteira).

Com relação ao conteúdo informacional, o portal está dividido em três partes (Anexo 1). À direita do site, está o seu conteúdo funcional, composto pela barra de menu, na qual a parte superior se acessa o conteúdo dinâmico de informações predominantemente gerenciais. Ao centro, está o seu conteúdo mais dinâmico, atualizado diariamente, representado pelas últimas notícias. $\mathrm{Na}$ terceira parte, localizada na parte inferior do site, está a seção radares técnicos, onde se encontram artigos técnico-científicos publicados por especialistas sobre temas da atividade leiteira. Além desses conteúdos, o portal ainda apresenta várias formas de interação com seus usuários, além de newsletter enviado diariamente.

Tabela 1 - Presença da informação gerencial e científica nas seções Cadeia Produtiva, Giro Lácteo e Radares Técnicos do Portal.

\begin{tabular}{c|c|c|c|c|c|c}
\hline \multirow{2}{*}{ Seções/ Links } & \multicolumn{4}{|c|}{ Natureza da Informação } & \multirow{2}{*}{ Total } & \multirow{2}{*}{ Base* $^{*}$} \\
\cline { 2 - 5 } & \multicolumn{1}{|c|}{ Informação Gerencial } & \multicolumn{2}{|c}{ Informação Gerencial } & & \\
\cline { 2 - 6 } Cadeia Produtiva & $\%$ & Número & $\%$ & Número & & \multirow{2}{*}{180} \\
\hline Giro Lácteo & 91,1 & 164 & 8,9 & 16 & 100,00 & 15 \\
\hline Radares Técnicos & 86,6 & 13 & 13,4 & 2 & 100,00 & 10 \\
\hline
\end{tabular}

Fonte: Dados da pesquisa.

* Base $=$ números absolutos que expressam as frequências registradas em cada um dos tipos de informação e em cada seção do site.

Nas seções em estudo, o predomínio é da informação gerencial com temáticas diversas, prevalecendo as informações ligadas ao mercado do leite. A Tabela 1 apresenta a distribuição dos dois tipos de informação - gerencial e científica - em cada seção do site. A informação gerencial tem forte presença nas seções Cadeia produtiva $(91,1 \%)$ e Giro Lácteo $(86,6 \%)$.

Apesar de possuir conteúdo mais diversificado, a seção Cadeia Produtiva tem somente $9 \%$ do conteúdo destinado à divulgação científica, de assuntos ligados à nutrição humana e à prevenção de doenças. Em razão de ter foco na divulgação de conteúdo técnico e científico, é apenas na seção Radares Técnicos que há predomínio da informação de natureza científica $(90,0 \%)$ sobre a informação gerencial $(10,0 \%)$, com foco em temas como animais jovens, conservação de forragens, gerenciamento, melhoramento genético, nutrição, pastagens, qualidade do leite, reprodução, sanidade e sistemas de produção. 
Tabela 2 - Tipos de informação gerencial e de informação cientifca publicados nas seções Cadeia Produtiva, Giro Lácteo e Radares Técnicos do Portal.

\begin{tabular}{c|c|c|c|c|c|c}
\hline \multirow{2}{*}{ Seções/ Links } & \multicolumn{3}{|c|}{ Tipos de informação gerencial } & \multicolumn{3}{c}{ Tipos de informação científica } \\
\cline { 2 - 7 } & Interna & Externa & Total & Artigos de divulgação & Matéria jornalística & Total \\
\hline Cadeia Produtiva & $13,4 \%$ & $\mathbf{8 8 , 6 \%}$ & $\mathbf{1 0 0} \%(164)$ & $\mathbf{8 7 , 5} \%$ & $12,5 \%$ & $100,00 \%(16)$ \\
\hline \multirow{2}{*}{ Giro Lácteo } & - & $100,00 \%$ & $100 \%(13)$ & - & $100,00 \%$ & $100,00 \%(2)$ \\
\hline Radares Técnicos & $100,00 \%$ & - & $100,00 \%(1)$ & $100,00 \%$ & - & $100,00 \%(9)$ \\
\hline
\end{tabular}

Fonte: Dados da pesquisa.

Observação: os números absolutos entre parênteses expressam isoladamente as frequências de ocorrência da informação gerencial e da informação científica, respectivamente, nas seções: Cadeia Produtiva, Giro Lácteo e Radares Técnicos.

A informação gerencial publicada é de origem externa nas seções Cadeia Produtiva $(86,6 \%)$ e Giro Lácteo (100,00\%), como demonstra a Tabela 2. A informação científica, por sua vez, privilegia os artigos de divulgação, nas seções
Cadeia Produtiva (87,5\%) e Radares Técnicos $(100,00 \%)$. Como era de esperar, devido ao seu caráter dinâmico e informativo, a seção Giro Lácteo emprega a linguagem jornalística noticiosa.

Tabela 3 - Distribuição do conteúdo das seções Cadeia Produtiva, Giro Lácteo e Radares Técnicos do Portal, segundo a natureza da fonte de informação.

\begin{tabular}{c|c|c|c|c}
\hline \multirow{2}{*}{ Seções/ Links } & \multicolumn{3}{|c|}{ Natureza da fonte de informação } & \multirow{2}{*}{ Total } \\
\cline { 2 - 5 } Cadeia Produtiva & Pública & Privada & Não identificada & \\
\hline \multirow{2}{*}{ Giro Lácteo } & $40 \%$ & $75 \%$ & $3 \%$ & $100 \%(180)$ \\
\hline Radares Técnicos & $60 \%$ & $30 \%$ & - & $100 \%(15)$ \\
& & & $10 \%$ & $100 \%(10)$ \\
\hline
\end{tabular}

Fonte: Dados da pesquisa.

Tendo em vista a natureza da fonte da informação, a Tabela 3 evidencia que as fontes privadas constituem maioria nas seções Cadeia Produtiva $(75,5 \%)$ e Giro Lácteo (60\%), provenientes das informações de agências de notícias e de jornais de grande circulação. Na seção Radares Técnicos, o predomínio é das fontes públicas $(60,0 \%)$, todas elas identificadas como instituições de ensino superior sediadas no Estado de São Paulo. 
Tabela 4 - Distribuição de conteúdo das seções Cadeia Produtiva, Giro Lácteo e Radares Técnicos do Portal, por natureza da informação e pela presença de elementos gráficos e audiovisuais.

\begin{tabular}{|c|c|c|c|c|c|c|c|c|}
\hline & \multicolumn{3}{|c|}{ Natureza da informaçäo } & \multicolumn{5}{|c|}{ Elementos gráficos e audiovisuais } \\
\hline & Opinativo & Informativo & Total & Linkagem & Dustração & $\begin{array}{l}\text { Espaço em } \\
\text { brance }\end{array}$ & $\begin{array}{l}\text { Video e/ou } \\
\text { animações }\end{array}$ & Base \\
\hline $\begin{array}{c}\text { Cadeia } \\
\text { Produtiva }\end{array}$ & $52 \%$ & $48 \%$ & $\begin{array}{l}100 \% \\
(180)\end{array}$ & $2 \%$ & $62 \%$ & $12 \%$ & $0,6 \%$ & 180 \\
\hline Giro Lácteo & - & $100 \%$ & $100 \%(15)$ & - & $7 \%$ & $7 \%$ & - & 15 \\
\hline $\begin{array}{l}\text { Radares } \\
\text { Técnicos }\end{array}$ & - & $100 \%$ & $100 \%(10)$ & - & $50 \%$ & $30 \%$ & - & 10 \\
\hline
\end{tabular}

Fonte: Dados da pesquisa.

Observação: Os números absolutos entre parênteses expressam as ocorrências em cada tipo das categorias de análise, dentro do universo total de frequências, de 180 na seção Cadeia Produtiva, 15 na seção Giro Leite e 10 na seção Radares Técnicos.

Como mostra a Tabela 4, a seção Cadeia Produtiva é a única com presença de informação de natureza opinativa (52\%), sendo exclusiva, nas demais, o gênero informativo. Em sua maioria, o conteúdo das seções tem poucas possibilidades de busca de informações adicionais do tipo "saiba mais", sendo detectados apenas links complementares (2\%) na seção Cadeia Produtiva. Nela, os conteúdos privilegiam, principalmente, elementos como gráficos, imagens e tabelas (62\%), todos eles utilizados como suporte visual nas informações apresentadas.

Quase inexistentes na seção Giro Lácteo (7\%), os elementos de ilustração são, também, significativos (50\%) na seção Radares Técnicos, mas nenhum conteúdo possui vídeo, ou link complementar, o que caracteriza umas escrita linear, com textos extensos e predomínio da rolagem da barra de navegação, o que torna a leitura mais cansativa.

\section{Considerações Finais}

As análises realizadas apontam para o fato de que as informações disponibilizadas no portal MilkPoint são lineares, ou seja, não dão ao usuário a oportunidade de aprofundar seus conhecimentos nos assuntos e temas apresentados, nem mesmo em assuntos correlatos, seguindo, fielmente, a tendência da escrita em papel. Assim, contraria a orientação de que a escrita na Web deve ser diferente do meio impresso, pois não se lê do mesmo jeito como se faz no papel. A partir desta constatação, pode-se dizer que os conteúdos na Web deveriam ser mistos, dando ao leitor a possibilidade de aprofundar conhecimentos durante a navegação, o que não acontece no caso do MilkPoint.

Os conteúdos são, em sua maioria, informativos. A exceção é a seção Cadeia Produtiva, principalmente, os links comércio internacional, conjuntura de mercado, dicas de sucesso, editorial e volta ao mundo, que possuem conteúdos opinativos em formato de carta de recomendação e artigo. Predominam, nos textos, informações gerenciais externas, exceto na seção Radares Técnicos. A maioria dos textos não utiliza separadores de conteúdo, como subtítulos e marcadores, e é extensa, razão da necessidade de rolagem da barra de navegação.

Enfim, pode-se dizer que o portal Milkpoint possui quantidade significativa de conteúdo, em comparação com outros sites da mesma área ${ }^{10}$; porém, precisa ser trabalhado esteticamente,

\footnotetext{
${ }^{10} \mathrm{O}$ portal Milkpoint pode ser comparado com outros sites como: ciência do leite, milknet, etc. quanto à quantidade e atualidade das informações divulgadas.
} 
apresentando mais elementos gráficos e explorar mais recursos audiovisuais como vídeos, muito apreciados pelo público rural. Além disso, devese avançar na utilização de escrita mista, com links ao longo dos textos para dar oportunidade ao leitor de se aprofundar no assunto que desejar. Por tratar-se de informação agropecuária, o mais importante talvez não seja a publicação instantânea do fato (notícia), pois, muito mais útil ao público desse conteúdo, devem ser a correta apuração e a boa análise dos fatos, de preferência com referências complementares que enriqueçam sua contextualização, o que seria facilitado pelo espaço virtual.

\section{Referências}

BARBOSA, A. C. L. S. Leitura e escrita na web. Linguagem em (Dis)curso, Tubarão, v. 5, n. 1, p. 153-183, jul./dez. 2004.

BLUME, R.; MACHADO, J. A. D. Tomada de decisão: o sistema de informações geográficas como ferramenta de apoio à gestão de propriedades rurais. In: CONGRESSO DA SOCIEDADE BRASILEIRA DE ECONOMIA E SOCIOLOGIA RURAL, 44., 2006, Fortaleza-CE. Anais... Fortaleza-CE, 2006.

BOTEON, M. Mercado de informação digital agronômica. 2004. 101 f. Tese (Doutorado em Economia Aplicada) - ESALQ/USP, Piracicaba, 2004.

CANAVILHAS, J. M. M. Do jornalismo online ao webjornalismo: formação para a mudança. Revista Comunicação e Sociedade, São Paulo, v. 9-10, p. 113-119, 2006.

CASTELLS, M. A sociedade em rede. São Paulo: Paz e terra, 1999.

CAVALCANTI, M. Marketing de conteúdo: obtendo resultados com internet e mídias sociais. 2010. Disponível em: <http://www.agripoint. com.br/ebook/100713-Marketing-internet-midiassociais-ebook.pdf>. Acesso em: 26 ago. 2012.

COUTO, L. E. D; MACEDO-SOARES, T. D. L. A. Três estratégias para turbinar a inteligência organizacional. Rio de Janeiro: FGV, 2004.
CHAIT, L. P. Se souber, conte a alguém. HSM Management, São Paulo, v. 14, 1999.

DUBE, J. Writing news online: a dozen tips. 2001. Disponível em: <www.cyberjournalist.net/tips. html>. Acesso em: 10 jun. 2012.

ESTEVÃO, P. Análise da web como fonte de informação cientifica e de interação entre pesquisa e extensão rural. 2011. 145 f. Dissertação (Mestrado em Extensão Rural) - Universidade Federal de Viçosa, Viçosa. 2011.

IBGE. Censo agropecuário 2006. 2006. Disponível em: <www.ibge.gov.br>. Acesso em: 10 jun. 2011.

. Acesso à internet no Brasil atinge 94,2 milhões de pessoas. 2012. Disponível em: <http:// www.ibope.com.br/pt-br/noticias/Paginas/Acessoa-internet-no-Brasil-atinge-94-milhoes-de-pessoas. aspx>. Acesso em: 3 ago. 2012.

INTERNATIONAL ORGANIZATION FOR STANDARDIZATION - ISO. ISO 9241-11: ergonomic requirements for office work with visual display terminals (VDTs). Part 11 - guidelines for specifying and measuring usability. Gènève: International Organisation for Standardisation, 1997.

LEFF, E. Aventuras da epistemologia ambiental: da articulação das ciências ao diálogo de saberes. Rio de Janeiro: Garamound, 2004. (Coleção Ideias Sustentáveis).

MASSARANI, L; MOREIRA, I. C. A retórica e a ciência: dos artigos originais à divulgação científica. Multiciência: Revista Interdisciplinar dos Centros e Núcleos da UNICAMP, Campinas, v. 4, maio 2005.

MEADOWS, A. J. A comunicação científica. Brasília: Briquet de Lemos, 1999.

MENDES, R. et al. Aplicação de critérios de seleção de informações na web. Porto Alegre: UFRGS, 2007.

NIELSEN, J.; LORANGER, H. Usabilidade na web: projetando websites com qualidade. Rio de Janeiro: Elsevier, 2007.

OLIVEIRA, M. O receptor na internet: dimensões interativas. Porto Alegre: Unisinos, 1997.

PINHO, J. B. Jornalismo na internet: planejamento e produção da informação on-line. São Paulo: Summus, 2003. 
$\overline{\mathrm{UFV}, 2} 006$.

REIS, G. O que é arquitetura de informação de websites? 2006. Disponível: <http://www.guilermo. com/ai_biblioteca/artigo.asp?referencia $=44>$. Acesso em: 12 jun. 2012.

RICH, C. Readability. 1999. Disponível em:<www. members.aol.com/crich13/readability.html>. Acesso em: 3 jul. 2012.

RODRIGUES, B. Arquitetura da informação. 2005. Disponível em: <http://webinsider.uol.com.br/ index.php/2005/05/06/arquitetura-da-informacao $>$. Acesso em: 12 jun. 2012.

SALAVERRIA, R. De la pirámide invertida al hipertexto. Revista Novática: Revista de la Asociación de Técnicos de Informática, Navarra, v. 142, p. 12-15, nov./dic. 1999.

SLATER, M. D; ROUNER, D. How message evaluation and source attributes may influence credibility assessment and belief change. Journalism and mass communication. Quarterly, Columbia, v. 73, n. 4, p. 974-991, 1996.

SORDI, J. O.; MEIRELES, M.; GRIJO, R. N. Gestão da qualidade da informação no contexto das organizações: percepções a partir do experimento de análise da confiabilidade dos jornais eletrônicos. Perspectivas em Ciência da Informação, Belo Horizonte, v. 13, n. 2, p. 168-195, maio/ago. 2008.

TOUB, S. Evaluating information architecture: a practical guide to assessing web site organization. 2000. Disponível em: <http://argus-acia.com/ white_papers/evaluating_ia.pdf $>$. Acesso em: 25 jul. 2012.

VEDDER, A; WACHBROIT, R. Reliability of informacion on the internet: some distinctions. Ethics and Informacion Technology, Dordrecht, v. 5, n. 4, p. 211-215, 2003.

VILELA, D.; BRESSAN, M.; CUNHA, A. S. (Ed.). Cadeia de lácteos no Brasil: restrições ao seu desenvolvimento. Brasília, DF: MCT/CNPq, 2001.

VIERO, V. C.; SOUZA, R. S. Comunicação rural on-line: promessa de um mundo sem fronteiras. In: CONGRESSO DA SOCIEDADE BRASILEIRA DE ECONOMIA, ADMINISTRAÇÃO E SOCIOLOGIA RURAL, 66., 2008, Rio BrancoAC. Anais... Rio Branco, 2008.
WIKIPEDIA. Portal (Internet). Disponível em: $<$ http://pt.wikipedia.org/wiki/Portal_(internet) $>$. Acesso em: 12 jun. 2012.

ZAMBONI, L. M. S. Cientistas, jornalistas e a divulgação científica: subjetividade $\mathrm{e}$ heterogeneidade no discurso da divulgação científica. Campinas: Autores Associados, 2001. 


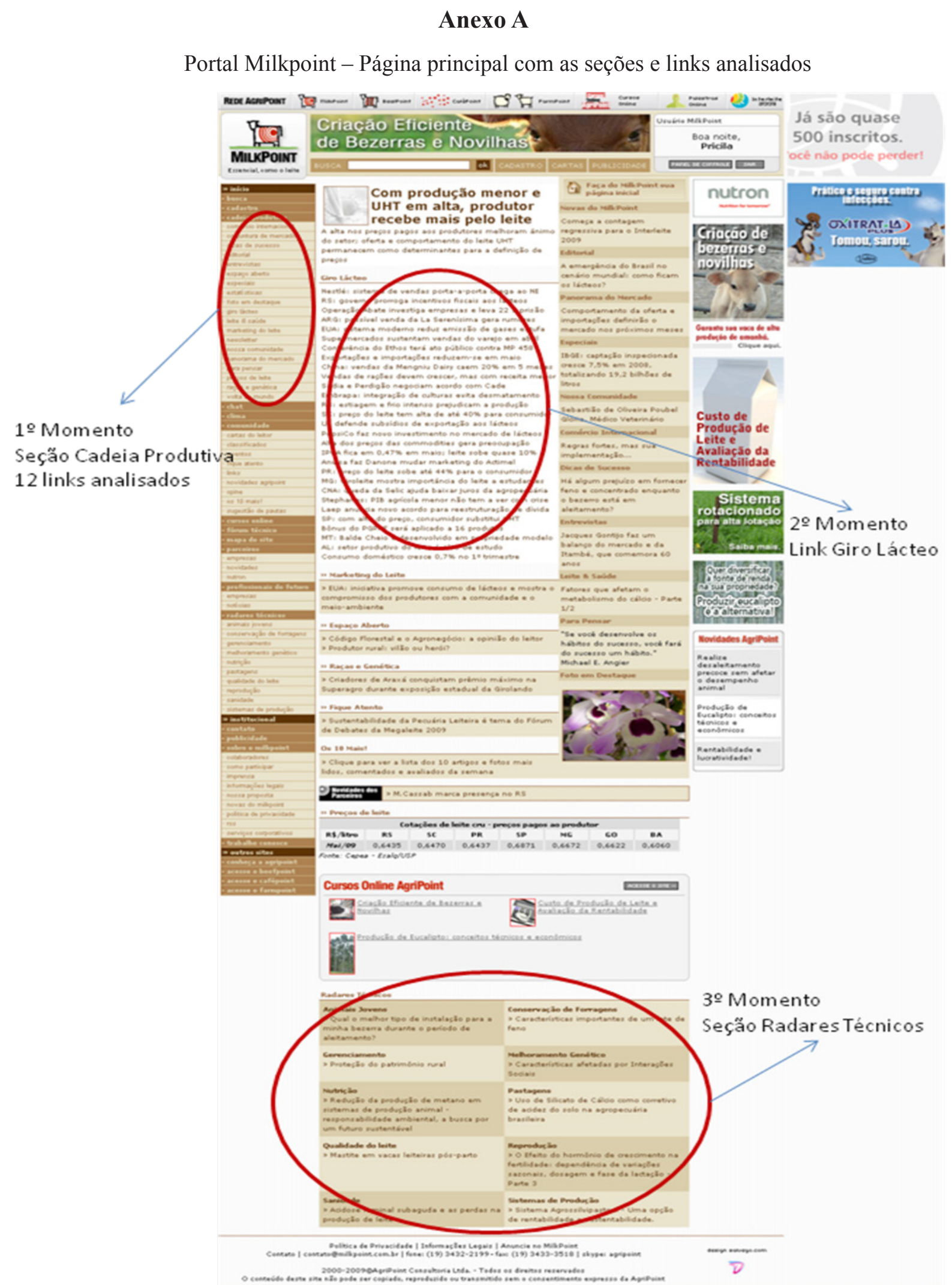

Recebido em: set. 2012

Aceito em: nov. 2012 
Estevão, P.; Sousa, D. N.; Pinho, J. B. 